\title{
EXPLORING PATENT ACTIVITY AND ITS POTENTIAL ASSOCIATION WITH HEALTHCARE OUTCOMES: A CASE STUDY OF OSTOMY PRODUCTS IN SWEDEN
}

Paul Samuel Calara

The Swedish Institute for Health Economics (IHE)

sc@ihe.se

\author{
Rikard Althin \\ The Swedish Institute for Health Economics (IHE) \\ Gary Inglese \\ Thomas Nichols \\ Global Health Economics, Hollister Incorporated
}

Objectives: The aim of this study was to evaluate whether ostomy industry patent activity (PA) is associated with patient outcomes and healthcare costs.

Methods: Two groups of ostomy pouch users based on manufacturer PA (low or high) were compared in terms of ostomy-related wear patterns, adverse events, and healthcare expenditure. Using Swedish registry data, all patients with newly formed stomas were divided between each group and were followed during a 2-year period (2011-12). Propensity score matching and parametric duration analysis were used to compare outcomes between patients of similar characteristics such as sex, age, and ostomy surgery type. Results: In both one- and two-piece systems, the high PA group had significantly lower monthly ostomy-related expenditure than the low PA group (one-piece: 197.47 EUR versus 233.34 EUR; two-piece: 164.00 EUR versus 278.98 EUR). Fewer pouch and skin wafer purchases per month were an important driver of cost differences. Both groups had similar likelihood of purchasing dermatological products for skin complications over time.

Conclusions: PA in the ostomy care industry was associated with reduced healthcare costs, but not necessarily with fewer skin complications. It suggests that there is a health economic benefit from products made by patent intensive companies which may differentiate them from generic comparators, but more research is needed to understand the impact of activities conducive to medical innovation on health outcomes.

Keywords: Ostomy, Patents, Utilization, Health care costs, Irritant dermatitis

Medical innovation has been a symbol of progress in the fight against diseases. Our prolonged human life spans in recent decades have been associated with the introduction of new drug launches and medical procedures (1-4). In Sweden, for instance, almost one-third of the increase in mean age at death between 1997 and 2010 has been attributed to the use of newly developed drugs (4). While "breakthrough" medical technologies have been shown to improve patient outcomes, health economists have sought to weigh the benefits of innovation against its costs, that is, evaluate its net benefit, in an effort to guide price and priority setting in the healthcare sector (5). Previous research suggest that medical innovation is cost-saving over time: the reduction in annual hospital expenses resulting from new technology outweigh the initial increases in annual pharmaceutical and other medical expenses $(3 ; 4)$.

Funding: This study has received financial support from Hollister Incorporated. Hollister Incorporated had no access to data. Compliance with ethical standards: This study was done in adherence to the Declaration of Helsinki guidelines and was approved by the Lund Ethical Review Board, Sweden (Dnr 2014/205). In accordance with this approval, the results of the study are required to be disseminated publicly. We thank Anna Forsblom (Skåne University Hospital) for providing support in identifying and categorizing ostomy cases in registries.
Insights into the impact of medical innovation have focused on patients, regions, and disease areas as the unit of observation (4). These studies have investigated, for example, whether regions who adopt relatively newer drugs have better outcomes than regions who adopt relatively older drugs (6). At the company level, there is little evidence regarding the impact patent activity (PA) has on patient outcomes and healthcare costs. Firms in the life sciences industry that invest more in research and development than their competitors could be delivering newer and more innovative products that produce greater societal benefits.

PA may provide a measure of innovative activity $(7 ; 8)$. Patents are granted to inventors by governments for the exclusive right of producing and marketing an invention for a limited period of time. In the medical industry, the patent system is thought of as a mechanism that incentivizes creating new and potentially economically valuable knowledge, whilst disseminating knowledge at the same time. Patents are granted under heavy scrutiny: inventors must assert the utility and marketability of their invention to be granted a patent. These aspects of the patent system, that is, pushing technological and scientific frontiers, and responding to commercial opportunities, are 
theorized as two important forces that induce innovation (9). However, not all innovations are patentable, nor would all new technical principles necessarily have equal economic significance (10). Furthermore, a share of patents may never become commercially viable products and processes in the medical industry. While not all innovations are patentable or impactful, expending efforts into patent creation signal that a firm is active in research and development.

This study examines the relationship of PA to patient outcomes and healthcare costs using ostomy-related patents as a proxy to measure this relationship. The ostomy care industry serves the needs of those with an ostomy (stoma), or ostomates; a surgical opening in the abdomen created for the purpose of eliminating waste from the bowel or bladder (11). The milieu for the stoma may be attributed to colon or bladder cancer, or for the management of severe bowel disease. The medical devices used by those with an ostomy includes pouches for the collection and containment of waste and odor, adhesive wafers adhering the pouch to the surgical opening, and a variety of accessory products to aid in maintaining the fit and function of the pouch and wafer.

It is hypothesized that high PA is associated with a decreased likelihood of adverse events and reduced healthcarerelated costs. The unit of observation in this study focuses on firms and their capacity to lead in the development of products that are differentiated and potentially perform better. Such firms may not necessarily be motivated to engage in innovative activities when faced with competitors that make cheaper alternatives.

In Sweden, health technology assessments (HTAs) often compare medical devices such as ostomy products with the cheapest alternative available in a given market (12-14). While a cheaper alternative may provide lower acquisition costs, a product with a higher price may still be more cost-effective if it can demonstrate better outcomes for patients and lower costs to the healthcare system over time. This study thus aims to ascertain those societal benefits in terms of cost savings and discuss its implications on health technology assessment. Using registry data on all new ostomates in Sweden, outcomes are compared between matched patients with similar characteristics such as age, sex, and ostomy surgery type.

\section{MATERIALS AND METHODS}

\section{Study Patients}

Observational patient data were collected for a 2-year period (2011 and 2012) from two Swedish national registries: the Patient registry (Patientregistret) and the Pharmaceutical registry (Läkemedelsregistret) $(15 ; 16)$. The registries contain records on transactions of medical products, and inpatient and outpatient hospital visits nationwide. All Swedish patients who had their first ostomy surgery between 2011 and 2012 were iden- tified and followed during this period. A stoma care nurse was consulted to identify surgical procedures that lead to stoma creation. A total of 3,883 patients with newly created stomas were identified. The total population was further categorized into three main types of ostomy surgeries: colostomy, ileostomy, and urostomy. Patients were excluded in this analysis if they had multiple stomas, did not purchase a prescribed ostomy product, or used multiple pouching systems upon hospital discharge.

\section{Patent Selection}

A search for U.S. and European patents and patent applications, abstracts of published Japanese patent applications, and published patent applications in the Patent Cooperation Treaty was conducted and cross-referenced for the years 2006 through 2011. The search was conducted by an independent third party. The search period (2006-11) was defined to be at least one year behind the 2-year period (2011-12) of the study to allow time for ostomy products to be available for patients. Based on the outcome of the search, ostomy product manufacturers were classified as either low or high PA manufacturers.

In total, 704 ostomy-related patents and patent applications, associated with ostomy pouches, wafers, and pouching system accessories were found within the search period. Of these, twenty-four patents and applications ( 3 percent) were attributed to single contributors with no identifiable industry association, and seventy-seven patents and applications (11 percent) were attributed to minor industry contributors. Single and minor industry contributors were excluded in patent selection because they are not directly involved in the manufacture of ostomy products and have only one patent or patent application found during the time period. After their exclusion, 603 patents and applications from ostomy product manufacturers remained.

High PA was conceived to occur in those manufacturers that have been the biggest contributors in creating ostomyrelated patents. Two distinct groups of manufacturers could be seen when manufacturers were ranked by percentage of total patents contributed. The top 5 percent of manufacturers in patent contribution were defined as the high PA group. Together, they were responsible for a total of 386 patents and applications (64 percent of all patents) with individual contributions ranging from 12 percent to 31 percent. Conversely, the bottom 95 percent of manufacturers were defined as the low PA group, which carried the remaining 217 patents and applications (36 percent). Each manufacturer in this group made relatively small contributions ranging from 0.3 percent to 4 percent. Manufacturers not present in Swedish registries during the study period were excluded, leaving seven manufacturers in the study. There were three manufacturers classified as high PA and four as low PA.

\section{Pouching Systems}

The type of system first purchased by patients was identified. Typically, the choice of the first pouching system is made by 
the patient in consultation with an ostomy nurse. Patients either first purchased a pouching system made by a low or high PA manufacturer (hereafter referred to as low or high PA pouch). Patients could switch between low and high PA pouches during the study period. A switch occurred when a patient purchased a different type of pouch to that which they first purchased (e.g., switching from a low to a high PA pouch). To verify that a switch was not a one-time product trial, a switch was further defined as two or more consecutive purchases of the new type of pouch, where the original pouching system had not been purchased at the same time.

The users of low and high PA pouches were further divided into three sub-groups: users of one-piece, two-piece, and mixed pouching systems. A one-piece pouching system is composed of an adhesive wafer with an integrated pouch while in a twopiece pouching system the adhesive wafer and the pouch are separate units. Patients that used both one-piece and two-piece systems during the study period were considered mixed system users.

\section{Propensity Score Matching}

Propensity score matching was used to identify and to compare outcomes with patients that have similar values on several observable characteristics in each group. Propensity scores are the conditional probability of being assigned treatment given a set of observed covariates (17). Conditional upon propensity scores, the distribution of these covariates or "conditioning" variables becomes balanced between treatment and control groups. In this analysis, we aimed to balance the distribution of sex, age, and type of ostomy surgery between low and high PA pouches.

We estimated propensity scores for each patient using a binary probit model with the "treatment" dependent variable, defined as using a low PA pouch or not, regressed on our set of three conditioning variables. To test for balance, we identified the optimal number of blocks to ensure the propensity score and conditioning variables were not different between patient groups in each block (18). Significant differences in means were tested with a two-sample $t$-test.

Each user of low PA pouches was matched to one user of high PA pouches with the same or closest propensity score. Once matched, the control individual was not matched again (without replacement matching). Because the control group (high PA) was more than five times larger than the treatment group (low PA), controls need not be used as matches for more than one treated individual to find similar scores (19). Matching was conducted in ascending order, assessing low scores first and rising to the closest or exact propensity score as the treated individual.

Ostomy-related wear patterns, adverse events, and healthcare expenditure were estimated for each matched pairs of patients using one-piece and two-piece pouching systems. The pharmacy selling price of purchased items excluding valueadded tax (VAT) and regional prices for outpatient visits were used to estimate costs in the analysis. One-tail $t$-tests were conducted to assess whether users of low PA pouches had higher mean estimates on these outcomes. Users of mixed pouching systems were not matched because matching would not balance the alternating use of one-piece and two-piece systems among patients in this group.

To explore the statistical significance of the nonnormally distributed results, we applied a bootstrap procedure $(20 ; 21)$ for both pouching systems. Bootstrap involves random resampling with replacement as a method to approximate the required standard deviation from the underlying sample distributions. It is a nonparametric method of statistical inference, used to compute approximate $p$-values.

\section{Sensitivity Analysis}

Matches could be made by pairing patients in ascending order as in the study, or in descending order were high propensity scores are assessed first before going down to lower scores. As the choice of order could affect which patients were matched (22;23), matching was also conducted in descending order as a sensitivity analysis.

\section{Parametric Duration Analysis}

Parametric duration analysis was used to estimate the time until the first incidence of peristomal skin complications (PSCs) occurred after surgery for each pouch type. Peristomal skin complications refer to irritated skin surrounding the stoma as a result of irritant dermatitis or contact between the dermatitis and wafer. These irritations can range from a mild dermatitis to more severe ulceration and disruption of the skin (24).

The purchase of skin products related to the treatment of a PSC was used to proxy a PSC event having occurred. Skin products included all products classified as dermatologicals (D category) in the Anatomical Therapeutic Chemical (ATC) classification system except for anti-psoriasis (D05 sub-category) and anti-acne (D10 sub-category) products (25). The KaplanMeier estimator was first used to plot empirical survival rates of patients over time to determine risk pattern between groups over time. To control for observable differences between each group of patients in pouching systems, parametric models were fitted on empirical survival plots. Similar to those used in matching estimators, conditioning variables included in parametric models were sex, age, ostomy surgery type, pouching system, and additionally pouch switching. A range of statistical distributions were considered for the parametric model to compare their projections. The selected model was judged to have good fit over the observed period of the study and had clinically plausible projections (26). 
Table 1. Descriptive Statistics: All Patients and Sub-groups

\begin{tabular}{lccc}
\hline & $\begin{array}{c}\text { All patients } \\
(n=3,680)\end{array}$ & $\begin{array}{c}\text { Low PA } \\
(n=437)\end{array}$ & $\begin{array}{c}\text { High PA } \\
(n=3,243)\end{array}$ \\
\hline Males, $n$ (\%) & $1,841(50 \%)$ & $183(42 \%)$ & $1,658(51 \%)$ \\
Age (years), median (IQR) & $68(59-77)$ & $69(58-78)$ & $68(59-76)$ \\
Type of ostomy & & & \\
$\quad$ Colostomy, $n(\%)$ & $1,951(53 \%)$ & $268(61 \%)$ & $1,683(52 \%)$ \\
Ileostomy, $n(\%)$ & $1,684(46 \%)$ & $165(38 \%)$ & $1,519(47 \%)$ \\
Urostomy, $n(\%)$ & $45(1 \%)$ & $4(1 \%)$ & $41(1 \%)$ \\
Pouching system & & & \\
One-piece system, $n(\%)$ & $1,802(49 \%)$ & $347(80 \%)$ & $1,456(45 \%)$ \\
Two-piece system, $n(\%)$ & $1,178(32 \%)$ & $37(8 \%)$ & $1,141(35 \%)$ \\
Mixed system, $n(\%)$ & $699(19 \%)$ & $53(12 \%)$ & $646(20 \%)$ \\
No. of patients who switched pouching system & $452(12 \%)$ & $148(34 \%)$ & $304(9 \%)$ \\
\hline
\end{tabular}

Note. IQR, interquartile range; $\mathrm{PA}$, patent activity.

\section{Outcome Measures}

Wear patterns were measured in terms of the average monthly number of purchases of skin wafers, pouches, and other ostomy accessories per patient. Ostomy accessories are aids to pouching systems designed to improve the fit of the wafer to the skin, thus helping to prevent leakage of effluent onto the skin which causes PSCs.

Average monthly wear patterns were first calculated by dividing the total number of purchases of an ostomy pouching system (pouch, skin wafer, or accessories) of a user by the total number of months observed after surgery of the user. This was then averaged over all patients in the same pouch type.

The average monthly number of skin products (dermatologicals) purchased and number of hospital outpatient visits per patient were used as proxies to measure the rates of PSC events. Hospital outpatient visits refer to visitations in dermatologyrelated wards in hospitals. Consultations with stoma care nurses were not captured by registry data and were thus not included in the analysis.

Monthly healthcare expenditure was divided into four categories for ostomy pouching systems: ostomy pouches and wafers, ostomy accessories, dermatologicals, and outpatient visits to dermatologists. Cost estimates from all categories were summed to calculate the total monthly expenditure for each pouching system. All estimates were calculated in Swedish kronor (SEK), adjusted to 2013 year prices using the consumer price index (CPI) (27), and then converted to 2013 euro (EUR) (conversion rate: $1 \mathrm{EUR}=8.65 \mathrm{SEK})(28)$.

The effect of pouching systems on the rate of PSC was shown in the estimated coefficients of the parametric model of PSC. Cumulative failure rates between pouching systems were also plotted over time to show the proportion of patients that used skin products over time after surgery.
Data analysis was performed using STATA and R statistical packages $(29 ; 30)$.

\section{RESULTS}

\section{Descriptive Statistics}

Of 3,883 patients with newly created stoma in 2011 and 2012, a total of 3,680 patients were included in the analysis. Patients who had multiple stoma $(n=121)$, who did not purchase a pouch product $(n=2)$, and who started with both low and high PA pouches $(n=80)$ were excluded.

Table 1 describes key characteristics of all included patients and in groups according to pouching system. Males composed half of all patients and the median age was 68 years old. Colostomies were the most common surgery conducted (53 percent), followed by ileostomies (46 percent), and urostomies (1 percent) in the full sample. Nearly half of all patients used one-piece systems (49 percent), followed by two-piece systems (32 percent), and mixed systems (19 percent).

The majority of patients ( 88 percent) first purchased a high PA pouch. Of all users of high PA pouches, 9 percent switched to a low PA pouch. Conversely, 34 percent of low PA users switched to a high PA pouch.

Before matching, there were significantly more males and proportionally more ileostomies in the high PA group than the low PA group for both one-piece and two-piece pouching systems. After matching, the distribution of sexes, age, and type of ostomy surgery were no longer significantly different between pouching systems.

\section{Monthly Wear Patterns and Rates of PSCs}

Table 2 reports monthly wear patterns and rates of PSCs after matching and bootstrapping. In one-piece systems 
Table 2. Monthly Utilization of Pouches, Skin Wafers, Ostomy Accessories, Skin Products, and Hospital Outpatient Visits per Patient by Pouching System

\begin{tabular}{|c|c|c|c|c|c|c|c|}
\hline \multirow[b]{2}{*}{ Variable } & \multirow[b]{2}{*}{ Unit } & \multicolumn{2}{|c|}{ One-piece system } & \multirow[b]{2}{*}{$p$-Value ${ }^{a}$} & \multicolumn{2}{|c|}{ Two-piece system } & \multirow[b]{2}{*}{$p$-Value ${ }^{a}$} \\
\hline & & $\begin{array}{c}\text { Low PA } \\
(n=347)\end{array}$ & $\begin{array}{c}\text { High PA } \\
(n=347)\end{array}$ & & $\begin{array}{c}\text { Low PA } \\
(n=37)\end{array}$ & $\begin{array}{c}\text { High PA } \\
(n=37)\end{array}$ & \\
\hline \multicolumn{8}{|c|}{ Wear patterns } \\
\hline & No. of pouches & $39.82(0.02)$ & $37.57(0.02)$ & $<.01$ & $43.26(5.53)$ & 35.55 (4.33) & $<.01$ \\
\hline & №. of skin wafers & $N A^{b}$ & $N A^{b}$ & & $13.26(1.56)$ & $10.73(1.15)$ & $<.01$ \\
\hline & №. of ostomy accessories & $2.79(<0.01)$ & $2.20(<0.01)$ & $<.01$ & $2.82(<0.01)$ & $2.16(0.01)$ & $<.01$ \\
\hline \multicolumn{8}{|l|}{ PSCS } \\
\hline & №. of skin products & $0.07(<0.01)$ & $0.08(<0.01)$ & 1.00 & $0.08(<0.01)$ & $0.05(<0.01)$ & $<.01$ \\
\hline & Hospital outpatient visits & $0.01(<0.01)$ & $0.01(<0.01)$ & 1.00 & $0.01(<0.01)$ & $0.02(<0.01)$ & 1.00 \\
\hline
\end{tabular}

Note. Values presented are means with bootstrapped standard errors within brackets.

aP-Value for one-tail t-test ( $\mathrm{H}_{0}$ : mean is higher for low PA group than for high PA group).

${ }^{b}$ One-piece systems have built-in skin wafers.

PA, patent activity; PSC, peristomal skin complications.

(integrated pouch/adhesive wafer), users of low PA pouches purchased 39.82 pouches and 2.79 accessory products per month, and users of high PA pouches purchased 37.57 pouches and 2.20 accessory products per month. The high PA group had significantly lower pouch and accessory use than the low PA group $(p<0.01)$.

In two-piece systems, users of low PA pouches purchased 43.26 pouches, 13.26 skin wafers, and 2.82 accessory products per month, and users of high PA pouches purchased 35.55 pouches, 10.73 skin wafers, and 2.16 accessory products per month. The high PA group had significantly lower pouch, skin wafer, and accessory use than the low PA group $(p<0.01)$.

The rate of PSCs were similar between groups as skin product purchases and hospital outpatient visits were infrequent: less than 1 in 10 patients would purchase a skin product and less than 1 in 50 patients would go to outpatient care. The high PA group had significantly lower skin product purchases for two-piece systems $(p<0.01)$, but not for one-piece systems. The high PA group did not have significantly fewer hospital visits than the low PA group for both one- and two-piece systems.

\section{Monthly Healthcare Expenditure}

Table 3 reports monthly expenditure on pouches, skin wafers, ostomy-related accessories, skin products, and hospital outpatient visits after matching and bootstrapping.

In one-piece systems, users of low PA pouches spent 169.84 EUR per month, and users of high PA pouches spent 151.41 EUR per month, a difference of 18.43 EUR or 11 percent less on average per month. In two-piece systems, users of low PA pouches spent 80.50 EUR per month on pouches and barriers, and users of high PA pouches spent 58.28 EUR, a difference of 22.22 EUR or 32 percent less on average per month. The high PA group had significantly lower pouch and skin barrier use than the low PA group for both one- and twopiece systems $(p<0.01)$. Differences in expenditure in twopiece systems may partly be due to higher prices for low PA pouches and skin barriers.

The cost of accessories, skin products, and hospital visits had relatively small impact on total monthly expenditure compared with the cost of pouching systems. Users of high PA pouches had significantly less monthly expenditure on ostomy accessories than users of low PA pouches for both oneand two-piece systems $(p<0.01)$. Users of high PA pouches had significantly less monthly expenditure on skin products for two-piece systems $(p<0.01)$, but not for one-piece systems. The high PA group did not have significantly less hospital expenditure than the low PA group for both one- and two-piece systems.

In total, healthcare expenditure was lower in the high PA group than the low PA group for both one- and two-piece systems. The cost savings of using high PA pouches as opposed to low PA pouches was 35.87 EUR per month per patient in one-piece systems and 114.98 EUR per month per patient in two-piece systems.

\section{Sensitivity Analysis}

When matching was conducted in descending order, the results did not differ from the main analysis where matching was conducted in ascending order. Users of high PA pouches had less frequent product use and lower expenditure to users of low PA pouches by similar margins. Rates of PSCs were not significantly different between groups (see Supplementary Tables 1 and 2). 
Table 3. Monthly Expenditure (EUR) of Pouches, Skin Wafers, Ostomy Accessories, Skin Products, and Hospital Outpatient Visits per Patient by Pouching System

\begin{tabular}{|c|c|c|c|c|c|c|c|}
\hline \multirow[b]{2}{*}{ Variable } & \multirow[b]{2}{*}{ Unit } & \multicolumn{2}{|c|}{ One-piece system } & \multirow[b]{2}{*}{$p$-Value ${ }^{a}$} & \multicolumn{2}{|c|}{ Two-piece system } & \multirow[b]{2}{*}{$p$-Value ${ }^{a}$} \\
\hline & & $\begin{array}{c}\text { Low PA } \\
(n=347)\end{array}$ & $\begin{array}{c}\text { High PA } \\
(n=347)\end{array}$ & & $\begin{array}{c}\text { Low PA } \\
(n=37)\end{array}$ & $\begin{array}{l}\text { High PA } \\
(n=37)\end{array}$ & \\
\hline \multicolumn{8}{|c|}{ Expenditure (EUR) ${ }^{b}$} \\
\hline & Pouches & $169.84(0.07)$ & $151.41(0.07)$ & $<.01$ & $80.50(9.25)$ & $58.28(7.28)$ & $<.01$ \\
\hline & Skin wafers & $N A^{c}$ & $N A^{c}$ & & 142.60 (19.30) & $66.58(9.87)$ & $<.01$ \\
\hline & Ostomy accessories & $51.87(0.04)$ & $43.95(0.03)$ & $<.01$ & $54.57(7.92)$ & $37.24(0.90)$ & $<.01$ \\
\hline & Skin products & $1.06(<0.01)$ & $1.30(<0.01)$ & 1.00 & $1.21(<0.01)$ & $0.72(<0.01)$ & $<.01$ \\
\hline & Hospital outpatient visits & $0.50(<0.01)$ & $0.85(<0.01)$ & 1.00 & $0.64(<0.01)$ & $1.34(<0.01)$ & 1.00 \\
\hline & Total expenditure & $233.34(0.09)$ & $197.47(0.08)$ & $<.01$ & $278.98(0.32)$ & $164.00(0.23)$ & $<.01$ \\
\hline
\end{tabular}

Note. Values presented are means with bootstrapped standard errors within brackets.

${ }^{a}$-Value for one-tail t-test ( $\mathrm{H}_{0}$ : mean is higher for low PA group than for high PA group).

${ }^{b}$ Consumer price index adjusted to 2013 year prices in Sweden.

'One-piece systems have built-in skin wafers.

PA, patent activity; EUR, Euro.

\section{Incidence of Skin Complications}

Empirical survival functions for each pouching system estimated using the Kaplan-Meier method showed a proportional hazards $(\mathrm{PH})$ risk pattern. A parametric survival function following the Gompertz distribution held the best fit on empirical data out of other distributions that followed the PH risk pattern (exponential and Weibull), and was thus chosen for the parametric model.

Of 3,680 patients with a newly formed stoma, 929 purchased skin products ( 25 percent of all patients). The likelihood ratio test statistic supports the model to be correctly specified ( $p$-value $<0.05$ ). The coefficient for the binary variable on users of low PA pouches was positive but not significantly different from zero indicating that the failure rates over time are the same between the two groups. All other coefficients do not show a significant effect on the rate of PSC except for age; greater age is associated with a higher rate of PSC. Figure 1 plots predicted cumulative failure rates over time for users of low and high PA pouches. Users of high PA pouches appeared to have marginally lower cumulative failure rates, that is, less proportion of them used dermatological products.

\section{DISCUSSION AND CONCLUSION}

Firms in the ostomy industry that were active in patent creation produced monetary benefits to consumers of their products, and to the healthcare system. Using a high PA pouch instead of a low PA pouch saved 35.87 EUR per month in one-piece systems and 114.98 EUR per month in two-piece systems. The cost-savings was derived mainly from the lower number of pouches and skin wafers purchased by users of high
PA pouches. No significant difference was observed in rates of PSCs between the two types of firms.

Although the findings showed little or no difference between the two groups in the incidence of PSCs, proxied by the purchase of skin products, it is notable that users of low PA pouches purchased more skin wafers and accessories as compared to users of high PA pouches. PSCs are a frequent (31-33) and costly complication in individuals with a stoma, yet little has been written on the health care usage and cost associated with these individuals (34-36). The management of PSCs often involves the use of additional ostomy pouching supplies as well as pharmacological products. The use of these additional supplies come at a cost. Users of high PA pouches were, therefore, able to achieve similar outcomes using fewer pouching supplies than users of low PA pouches. Furthermore, high PA pouches being a lower cost alternative may be associated to the significant proportion of users of low PA pouches that switched to high PA pouches (34 percent). Regardless of the product groups used, products that address leakage and skin complications remains an unmet need.

A strength of register-based studies is that purchasing patterns of ostomy pouching systems can be investigated in a relatively fast and inexpensive way. The advantage of Swedish Patient and Pharmaceutical registries is that they cover the entire population, thus eliminating issues relating to drawing a representative sample. Furthermore, the first pouch purchase of patients in the study could be identified. Willingness-to-pay studies evaluating different pouches note that patients with ostomies tend to place value on staying on their current pouching system even if another system produces better outcomes (37). By identifying the first pouch purchase, pouch switching was 
Calara et al.

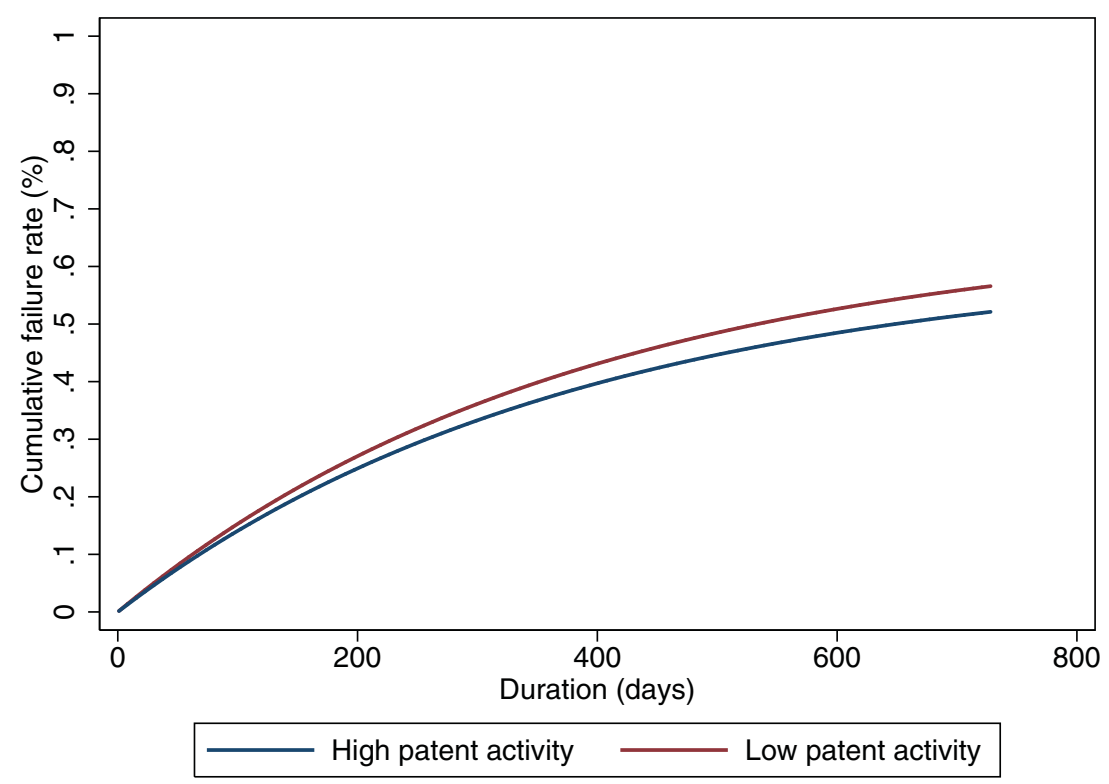

Figure 1. Gompertz model of peristomal skin complications (PSCS) by low and high patent activity (PA) groups. No significant difference in rates of PSC were found between groups.

analyzed when patients have least adapted to their pouching system.

There were several limitations in this study, some of which are inherent to its register-based design. The event of PSCs could not be observed directly from registry data and thus we relied instead on a proxy measure to determine their incidence. Unlike other national markets, Sweden is primarily a one-piece ostomy market. With few users of two-piece pouching systems in the Swedish market, our sample size for the two-piece group was small. Nonetheless, bootstrapping methods were applied to account for the limited sample size. The two-piece ostomy market may be under-represented in this study.

The use of propensity score matching controls for observed confounding factors influencing product selection and consumption. Heterogeneity in unobserved factors may be unaccounted for.

Consultations with stoma care nurses were not captured by registry data. This important cost item and indicator of PSCs was, therefore, not included in the analysis. Monthly ostomyrelated expenditure is expected to be underestimated; however, it is not expected that the PA groups differ significantly on the number of consultations with nurses. The study relied on the use of a proxy measure (the purchase of dermatologicals) to determine the presence of PSCs. Different levels of disease severity were not captured using this measure.

Medical innovation could be measured using other methods. In the Lichtenberg studies on pharmaceutical innovation, innovation was measured, for instance, using a concept of "vintage" derived from the studies of Solow on the role of technology on inducing economic growth (4). Given the lack of public records on the innovative activities of private firms, publicly available patents records were deemed a satisfactory indicator of the innovativeness of medical device firms.

This was the first study that we have seen on estimating the benefits of medical innovation in a medical device industry. Previous studies regarding the pharmaceutical industry nonetheless have drawn a similar conclusion that medical innovation lowers healthcare costs. In some studies, the acquisition cost of new medical technology has been asserted to have been offset by lower overall healthcare costs. It is outside the scope of this study to determine whether the cost of creating and acquiring new patents are outweighed by the benefits ostomates derive from using products of innovative firms. But what has been observed is that patients may benefit from using ostomy products from innovative firms.

HTA authorities may view medical products, particularly medical devices, as interchangeable unless there is evidence of the extra benefit in using products from high PA firms. In this system, the choice of comparator is often based on the cheapest alternative available (12-14) As we observed here, the health care cost of the high PA group was lower over a 2-year period, indicating additional benefits compared with the low PA group. Firms that have a higher cost base for doing research and innovation may perform better than firms that are less engaged in it when outcomes are measured over a longer period of time. Such measurement of outcomes would ensure that the cheapest available comparator is evaluated for its long-term value and not only for their short-term benefit of lower acquisition costs.

In conclusion, greater PA in the ostomy care industry was found to be associated with reduced healthcare costs, but not necessarily with fewer skin complications. Although ostomy pouching systems all have the same primary function as effluent collectors, they may result in different healthcare costs for 
patients. Analyzing real world data suggests that this difference could, in part, arise from medical innovation, as represented by PA in medical companies.

\section{SUPPLEMENTARY MATERIAL}

Supplementary Table 1: https://doi.org/10.1017/S0266462317000435

Supplementary Table 2:

https://doi.org/10.1017/S0266462317000435

\section{CONFLICTS OF INTEREST}

Paul Samuel Calara and Rikard Althin declare that they have no conflict of interest. Gary Inglese and Thom Nichols are employees of Hollister Incorporated. All authors contributed to the design of the study. Paul Samuel Calara and Rikard Althin undertook data analyses and determined the final study design. Hollister Incorporated had no role in the decision to submit the manuscript for publication.

\section{REFERENCES}

1. Lichtenberg FR. The impact of new drug launches on longevity: Evidence from longitudinal, disease-level data from 52 countries, 19822001. Int J Health Care Finance Econ. 2005;5:47-73.

2. Lichtenberg FR. The effect of new cancer drug approvals on the life expectancy of American cancer patients, 1978-2004. Econ Innov New Technol. 2009;18:407-428.

3. Lichtenberg FR. The impact of therapeutic procedure innovation on hospital patient longevity: Evidence from Western Australia, 2000-2007. Soc Sci Med. 2013;77:50-59.

4. Lichtenberg FR, Pettersson B. The impact of pharmaceutical innovation on longevity and medical expenditure in Sweden, 1997-2010: Evidence from longitudinal, disease-level data. Econ Innov New Technol. 2014;23:239-273.

5. de Pouvourville G. Innovation as a major research issue in health economics. Eur J Health Econ. 2001;2:139-141.

6. Lichtenberg FR. Contribution of pharmaceutical innovation to longevity growth in Germany and France, 2001-7. Pharmacoeconomics. 2012;30:197-211.

7. Griliches Z. Patent statistics as economic indicators: A survey. Nashville, TN: American Economic Association; 1990:1661.

8. OECD. Patents as statistical indicators of science and technology. In: OECD Patent Statistics Manual. Paris: OECD Publishing; 2009.

9. Kline SJ, Rosenberg N. An overview of innovation. Stanford, CA: Stanford University; 1986.

10. Smith K. Measuring innovation. In: Fagerberg J, Mowery DC, Nelson RR, eds. The Oxford handbook of innovation. Oxford: Oxford University Press; 2009.

11. Agarwal S, Ehrlich A. Stoma dermatitis: Prevalent but often overlooked. Dermatitis. 2010;21:138-147.

12. The Dental and Pharmaceutical Benefits Agency (TLV). Läkemdelsförmånsnämndens allmänna råd om ekonomiska utvärderingar. Stockholm: The Dental and Pharmaceutical Benefits Agency (TLV); 2003. Swedish.

13. The Dental and Pharmaceutical Benefits Agency (TLV). Handbok till Tandvårds- och läkemdelsförmånsverkets föreskrifter (TLVFS 2011:3) om ansökan om pris och subvention för förbrukningsartiklar. Stockholm: The Dental and Pharmaceutical Benefits Agency (TLV); 2011. Swedish.

14. The Dental and Pharmaceutical Benefits Agency (TLV). Ändring $i$ Läkemdelsförmånsnämndens allmänna råd (LFNAR 2003:2) om ekonomiska utvärderingar. Stockholm: The Dental and Pharmaceutical Benefits Agency (TLV); 2015. Swedish.

15. Ludvigsson JF, Andersson E, Ekbom A, et al. External review and validation of the Swedish national inpatient register. BMC Public Health. 2011;11:450.

16. Wettermark B, Hammar N, Fored CM, et al. The new Swedish Prescribed Drug Register-Opportunities for pharmacoepidemiological research and experience from the first six months. Pharmacoepidemiol Drug Saf. 2007;16:726-735.

17. Rosenbaum P, Rubin D. The central role of the propensity score in observational studies for causal effects. Biometrika. 1983;70:41-55.

18. Becker S, Ichino A. Estimation of average treatment effects based on propensity scores. Stata J. 2002;9:358-377.

19. Baser O. Too much ado about propensity score models? Comparing methods of propensity score matching. Value Health. 2006;9:377-385.

20. Efron B. Bootstrap methods: Another look at the jackknife. Ann Stat. 1979;7:1-26.

21. Manly BFJ. Randomization, bootstrap and Monte Carlo methods in biology. 2nd ed. London: Chapman \& Hall; 1997.

22. Stuart EA. Matching methods for causal inference: A review and a look forward. Stat Sci. 2010;25:1-21.

23. Stuart EA, Ialongo NS. Matching methods for selection of subjects for follow-up. Multivariate Behav Res. 2010;45:746-765.

24. Nybaek H, Jemec GB. Skin problems in stoma patients. J Eur Acad Dermatol Venereol. 2010;24:249-257.

25. WHO Collaborating Centre for Drug Statistics Methodology. Guidelines for ATC classication and DDD assignment. Oslo: WHO; 2014.

26. Ishak KJ, Kreif N, Benedict A, Muszbek N. Overview of parametric survival analysis for health-economic applications. Pharmacoeconomics. 2013;31:663-675.

27. Statistics Sweden. Consumer Price Index (CPI). Statistics Sweden; 2016.

28. Riksbanken. Räntor \& valutakurser. Riksbanken; 2016. Swedish.

29. R Core Team. R Statistical Package: Version 3.3.0. Vienna: R Foundation for Statistical Computing; 2015.

30. StataCorp. Stata statistical software: Release 14. College Station, TX: StataCorp LP; 2015.

31. Colwell JC, Ratliff CR, Goldberg M, et al. MASD part 3: Peristomal moisture- associated dermatitis and periwound moisture-associated dermatitis: A consensus. J Wound Ostomy Continence Nurs. 2011;38:541553; quiz 554-555.

32. Herlufsen P, Olsen AG, Carlsen B, et al. Study of peristomal skin disorders in patients with permanent stomas. Br J Nurs. 2006;15: 854-862.

33. Andersen BD, Keizerswaard Pv, Castro MM, English E, Carter D. Introduction to the DialogueStudy: Methods and baseline demographic findings. Gastrointestinal Nursing. 2011;9(Suppl 2):S4-S8.

34. Gore JL, Lai J, Gilbert SM. Readmissions in the postoperative period following urinary diversion. World J Urol. 2011;29:79-84.

35. Tyler JA, Fox JP, Dharmarajan S, et al. Acute health care resource utilization for ileostomy patients is higher than expected. Dis Colon Rectum. 2014;57:1412-1420.

36. Wick EC, Shore AD, Hirose K, et al. Readmission rates and cost following colorectal surgery. Dis Colon Rectum. 2011;54:1475-1479.

37. Bonnichsen O. Elicitation of ostomy pouch preferences: A discretechoice experiment. Patient. 2011;4:163-175. 